\title{
Neuromedin B receptor disruption impairs adipogenesis in mice and 3T3-L1 cells
}

\author{
Gabriela Silva Monteiro de Paula1, Marianna Wilieman', Karina Ribeiro Silva1,2,3, Leandra Santos Baptista²,3 \\ Sihem Boudina4, Luana Lopes de Souza1, Thais Bento-Bernardes ${ }^{1}$, Karina Dutra Asensi ${ }^{5,6}$, \\ Regina Coeli dos Santos Goldenberg 5 and Carmen Cabanelas Pazos-Moura1
}

\begin{abstract}
1Molecular Endocrinology Laboratory, Institute of Biophysics Carlos Chagas Filho, Federal University of Rio de Janeiro, Rio de Janeiro, Brazil 2Post-Graduation Program of Biotechnology, National Institute of Metrology, Quality and Technology - INMETRO, Rio de Janeiro, Brazil ${ }_{3}^{3}$ Multidisciplinary Center for Biological Research (Numpex-Bio), Federal University of Rio de Janeiro - Campus of Duque de Caxias, Rio de Janeiro, Brazil ${ }^{4}$ Department of Nutrition and Integrative Physiology, University of Utah School of Medicine, Salt Lake City, Utah, USA ${ }^{5}$ Cellular and Molecular Cardiology Laboratory, Institute of Biophysics Carlos Chagas Filho, Federal University of Rio de Janeiro, Rio de Janeiro, Brazil ${ }^{6}$ National Center of Structural Biology and Bioimage - CENABIO, Federal University of Rio de Janeiro, Rio de Janeiro, Brazil
\end{abstract}

Correspondence should be addressed to C C Pazos-Moura: cpazosm@biof.ufrj.br

\begin{abstract}
Neuromedin B, a bombesin-like peptide, and its receptor, are expressed in white adipose tissue with undefined roles. Female mice with disruption of neuromedin $B$ receptor (NB-R) exhibited partial resistance to diet-induced obesity leading to our hypothesis that NB-R is involved in adipogenesis. Here, we showed that adipose stem/stromal cells (ASC) from perigonadal fat of female NB-R-knockout mice, exposed to a differentiation protocol in vitro, accumulated less lipid (45\%) than wild type, suggesting reduced capacity to differentiate under adipogenic input. To further explore mechanisms, preadipocytes 3T3L1 cells were incubated in the presence of NB-R antagonist (PD168368) during the first 3 days in culture. Cells were analyzed in the end of the treatment (Day 3) and later when fully differentiated (Day 21). NB-R antagonist induced lower number of cells at day 3 and $21(33-39 \%)$, reduced cell proliferation at day $3(-53 \%)$ and reduced lipid accumulation at day $21(-86 \%)$. The mRNA expressions of several adipocyte differentiation markers were importantly reduced at both days: Cebpb and Pparg and Fabp4, Plin-1 and Adipoq, and additionally Lep mRNA at day 21. The antagonist had no effect when incubated with mature 3T3-L1 adipocytes. Therefore, genetically disruption of NB-R in mice ASC or pharmacological antagonism of NB-R in 3T3-L1 cells impairs adipogenesis. The mechanisms suggested by results in 3T3-L1 cells involve reduction of cell proliferation and of early gene expressions, leading to decreased number of mature adipocytes. We speculate that NB-R antagonism may be useful to limit the increase in adiposity due to pre-adipocyte differentiation.
\end{abstract}

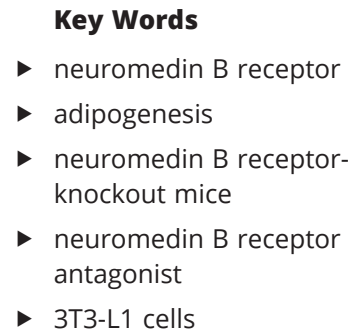

Journal of Molecular Endocrinology (2019) 63, 93-102

\section{Introduction}

Neuromedin B (NB) and gastrin-releasing peptide (GRP), bombesin-similar peptides, are found in several tissues of mammals (McDonald et al. 1979, Minamino et al. 1983), where they exert local regulatory actions, concerning a wide array of processes, including endocrine secretion and cell proliferation (Oliveira et al. 2006, Park et al. 
2011, Kameda et al. 2014, Ma et al. 2018). Bombesinlike receptors are $G$ protein-coupled receptors, the NB preferential receptor (NB-R), (von Schrenck et al. 1989), the GRP preferential receptor (GRP-R), (Spindel et al. 1990) and BRS-3, bombesin receptor subtype 3 (Gorbulev et al. 1992), an orphan receptor that has very low affinity for NB and GRP.

Bombesin-like receptors have been implicated in the regulation of the energy homeostasis, as suggested by studies in animals with genetically disrupted receptors. BRS3-knockout mice are obese, have insulin resistance, hyperleptinemia and impaired glucose metabolism (Ohki-Hamazaki et al. 1997). GRP-R-knockout mice are hyperphagic and presented higher adiposity only at very old ages (Ladenheim et al. 2002). In contrast, we demonstrated NB-R-knockout mice (NBR-KO) fed a regular chow exhibited normal body weight and better glucose tolerance (Paula et al. 2016). However, female NBR-KO mice exhibited a partial resistance to high-fat diet-induced obesity (Paula et al. 2010), not associated with hyperphagia, neither with glucose intolerance.

Neuromedin B receptor was found in visceral white adipose tissue (Yang et al. 2003), while neuromedin B is highly expressed in mice and human visceral and subcutaneous white adipose tissue (Hoggard et al. 2007); however, there is no defined role for neuromedin B or its receptor in the white adipose tissue. The lower accumulation of fat mass observed in female NBR-KO mice in response to the high-fat diet led us to raise the question whether NB-R may be involved in adipogenesis. The finding that NB mRNA has a peak of expression in 3T3-L1 cells during the first 2 days in the presence of adipogenesis inductors in vitro (Hoggard et al. 2007) reinforces this possibility. Here, we tested the ability of adipose stem/stromal cells (ASCs) from visceral adipose tissue of the perigonadal region of female NB-RKO mice to differentiate under adipogenic stimuli in vitro. In addition, to further explore mechanisms, we tested the effect of blocking the NB-R, employing a pharmacology antagonist, on the ability of the committed preadipocyte cell line, 3T3-L1 cells to differentiate in response to a mixture of prodifferentiative agents.

\section{Materials and methods}

\section{Animals}

Heterozygous C57BL/6 mice with deletion for neuromedin $\mathrm{B}$ receptor were bred and offspring genotyped by PCR, as described before (Ohki-Hamazaki et al. 1999). Mice were kept in light-darkness cycle (7:00 h and 19:00h) with controlled temperature $\left(24^{\circ} \mathrm{C}\right)$ and ad libitum water and standard chow (Bio-Tec Biobase Alimentação Animal LTDA, Florianópolis, SC, Brazil). The Ethics Committee in Animal Use of the Health Sciences Center from Federal University of Rio de Janeiro has approved all experiments (CEUA 045/15).

\section{Evaluation of adipogenic differentiation of ASC from white perigonadal adipose tissue of NBR-KO mice}

Perigonadal adipose tissue depots from 5-month-old WT and neuromedin B receptor-knockout (NBR-KO) female mice (eight animals for group with paired weight) were extracted and pooled in a tube for each genotype group. A small piece was separated for RNA extraction. For cell culture, adipose tissue depots were cut into small pieces and digested with collagenase IA (Sigma-Aldrich ${ }^{\circledR}$ ). Cells were harvested by centrifugation and plated in tissue culture flasks with Mesencult ${ }^{\mathrm{TM}}$ medium (Stem Cell Technologies, Vancouver, Canada) at $37^{\circ} \mathrm{C}$ in a humid atmosphere with $5 \% \mathrm{CO}_{2}$. Culture medium was changed every 3 days until the cell monolayer reached confluence. ASC isolated from perigonadal depots of WT and NBR-KO animals were induced to adipogenic lineage $(n=2)$ by culturing $2 \times 10^{4} / \mathrm{cm}^{2}$ in triplicates under Mesencult ${ }^{\mathrm{TM}}$ medium supplemented with adipogenic cocktail consisting of $0.5 \mathrm{mM}$ isobutylmethylxanthine (IBMX), $1 \mu \mathrm{M}$ dexamethasone, $200 \mu \mathrm{M}$ indomethacin (all from Sigma-Aldrich ${ }^{\circledR}$ ) and $10 \mu \mathrm{g} / \mathrm{mL}$ insulin (regular insulin, Lilly ${ }^{\circledR}$, Indianapolis, IN, USA). After 3 days of induction, cells were maintained under Mesencult ${ }^{\mathrm{TM}}$ medium supplemented with $1 \mu \mathrm{g} / \mathrm{mL}$ insulin for until 7 days. Control groups of undifferentiated cells were maintained without adipogenic cocktail or insulin.

Adipogenic differentiation was quantified using Oil Red O staining. ASC monolayers were fixed with $4 \%$ of buffered paraformaldehyde (Merck) for $1 \mathrm{~h}$ at room temperature and then incubated with Oil Red O (SigmaAldrich $^{\circledR}, 5 \mathrm{mg} / \mathrm{mL}$ in $70 \%$ ethanol) for $1 \mathrm{~h}$, and thereafter washed with PBS. Images were obtained by a digital camera coupled to an optical microscope (Axiophot, Zeiss). The stain was dissolved with isopropanol for $10 \mathrm{~min}$ and its absorbance was measured in a spectrophotometer at $490 \mathrm{~nm}$. The absorbance of all cells was subtracted from the values obtained with the isopropanol background. 
Effect of neuromedin B receptor antagonist PD168368 on the adipocyte differentiation of 3T3-L1 lineage cells

3T3-L1 cells, obtained from Rio de Janeiro Cell Bank (BCRJ Cat \#0019, RRID:CVCL_0123 -Duque de Caxias, Rio de Janeiro, Brazil), were kept in $5 \% \mathrm{CO}_{2}$ at $37^{\circ} \mathrm{C}$ atmosphere for expansion with growth medium: DMEM high glucose, $10 \%$ calf serum, $100 \mathrm{U} / \mathrm{mL}$ penicillin and $100 \mu \mathrm{g} / \mathrm{mL}$ streptomycin $\left(\mathrm{Gibco}^{\circledR}\right)$. After $70 \%$ of confluence, cells were plated $\left(10^{4} / \mathrm{cm}^{2}\right.$ in 6 well plate or $3 \times 10^{4} / \mathrm{cm}^{2}$ in 96-well plate), and when reaching $90 \%$ of confluence, cells were arbitrary separated in four groups: undifferentiated (UND), differentiated control (DIFF CTR), differentiated with the antagonist vehicle 0.03\% DMSO (DIFF DMSO dimethylsulfoxide, Merck) and differentiated with $3 \mu \mathrm{M}$ of neuromedin B receptor antagonist PD168368, diluted at $0.03 \%$ DMSO, present in culture from day 1 to 3 (DIFF ANTAG, Santa Cruz Biotechnology). Undifferentiated group was cultured in incubation medium alone: DMEM high glucose, 5\% fetal bovine serum (SAFC ${ }^{\circledR}$, St Louis, MO, USA), $100 \mathrm{U} / \mathrm{mL}$ penicillin and $100 \mu \mathrm{g} / \mathrm{mL}$ streptomycin. Differentiated groups were cultured in medium plus adipogenic cocktail containing $0.5 \mu \mathrm{M}$ IBMX, $1 \mu \mathrm{M}$ dexamethasone and $10 \mu \mathrm{g} / \mathrm{mL}$ insulin, during 3 days. Thereafter, differentiated groups were maintained in incubation medium plus $10 \mu \mathrm{g} / \mathrm{mL}$ insulin until 21 days of incubation (Fig. 3A), with medium changed every 2-3 days. At D3 and D21, cells from 96-well plates were fixed in $4 \%$ PFA (paraformaldehyde) and from six-well plates were harvested for RNA extraction. Passage number was limited to 15 in all experiments.

\section{Effect of neuromedin B receptor antagonist PD168368 on mature 3T3-L1 cells}

Cell differentiation followed the protocol described above until day 21, when they were divided into three groups: differentiated control (DIFF CTR), differentiated with $0.03 \%$ DMSO (DIFF DMSO) and differentiated with $3 \mu \mathrm{M}$ of neuromedin B receptor antagonist PD168368, diluted with $0.03 \%$ DMSO (DIFF ANTAG). Cells were cultured with medium plus insulin for 6 days, with medium changed once after 3 days. One group was maintained in incubation medium alone as undifferentiated control (UND). At day 27, culture cells were fixed or had RNA extracted.

Each experimental design was developed through the same time but there were four replicates for each analysis. Six-well plate was used for RNA extraction and gene expression analysis and repeated four times. 96-well plate experiments were conducted 12 times: nuclear and lipid staining (same wells), MTT cell viability assay and BrdU incorporation assay -four replicates each.

\section{Nuclear and lipid staining}

After fixation, cells from 96-well plate were stained with DAPI (1:2000 in PBS, 4',6-diamidine-2'-phenylindole dihydrochloride - Sigma-Aldrich ${ }^{\circledR}$ for nuclear

Table 1 Sequences of primers used for mRNA analysis.

\begin{tabular}{l}
\hline Primers \\
\hline Acaca \\
Adipoq \\
Cebpa \\
Cebpb \\
Cebpd \\
Fabp4 \\
Grp \\
Grpr \\
Hprt \\
Lep \\
Nmb \\
Nmbr \\
Plin1 \\
Pparg \\
Rplp0 \\
Srebf1 \\
\hline
\end{tabular}

\begin{tabular}{l} 
sequences $\mathbf{5}$ '-3'-foward \\
\hline GCCTTACAGGATGGTTTGGCCTTT \\
CACCCTTAGGACCAAGAAG \\
GTAACCTTGTGCCTTGGATACT \\
GGGCCCTGAGTAATCACTTAAA \\
GGACTGCGAGAGAAGCTATATT \\
AGCTCCTCCTCGAAGGTTTA \\
GCTGTGGGACACTTAATGGGA \\
GGCTGACAGGTGGCTATTT \\
GCAGTACAGCCCCAAAATGG \\
GGCTTTGGTCCTATCTGTCTTAT \\
GCAGATCATGACTCAGCTGTAG \\
CCCTACCCACAAACAGATGAG \\
GTGCTTCCAGAAGACCTACAA \\
GAACCTGCATCTCCACCTTATT \\
GGCCCTGCACTCTCGCTTTC \\
GTGTCTATGGAGGGCATGAAA
\end{tabular}

\begin{tabular}{l}
\hline sequences $\mathbf{5}^{\prime}$-3'-reverse \\
\hline AACAAATTCTGCTGGCGAAGCCAC \\
CAAGGGAACTTGTGCAGG \\
GGTGAGGACACAGACTCAAATC \\
CACTTTAATGCTCGAAACGGAAA \\
GCGCAGTCTCTTCCTCTTATC \\
CTGTCGTCTGCGGTGATTT \\
CCTTGAGAACCTGGAGCAGA \\
GGCACAACTAATGAAGGTTTGG \\
AACAAAGTCTGGCCTGTATCCAA \\
ATTCTCCAGGTCATTGGCTATC \\
CAAGATTCGAGTGCACCCT \\
CAGCCCACAAAGACCAGAA \\
CTTCAGTTCAGAGGCGATCTT \\
CGGCAGTTAAGATCACACCTATC \\
TGCCAGGACGCGCTTGT \\
GCATCAGAGGGAGTGAGAATG
\end{tabular}

Acaca, acetyl-CoA carboxylase alpha; Adipoq, adiponectin; Cebpa, CCAAT/enhancer-binding protein alpha; Cebpb, CCAAT/enhancer-binding protein beta; Cebpd, CCAAT/enhancer-binding protein delta; Fabp4, fatty acid-binding protein 4; Grp, GRP; Grpr, GRP receptor; Hprt, hypoxanthine phosphoribosyltransferase 1; Lep, leptin; $\mathrm{Nmb}$, neuromedin B; Nmbr, neuromedin B receptor; Plin1, perilipin type 1; Pparg, peroxisome proliferator activated receptor gamma; Rplp0, ribosomal protein lateral stalk subunit PO - 36B4; Srebf1, sterol regulatory element-binding transcription factor 1.

https://jme.bioscientifica.com

https://doi.org/10.1530/JME-19-0032
(C) 2019 Society for Endocrinology Published by Bioscientifica Ltd. Printed in Great Britain 
quantification. BODIPY ${ }^{\circledR}$ staining $(1: 20.000$ in $0.5 \mathrm{M}$ KI (Potassium iodide) - 4,4 - Difluoro-1,3,5,7,8 - Pentamethyl - 4 - Bora - 3a, 4a - Diaza - s - Indacene, 493/503, Thermo Fisher Scientific) was conducted to check lipid accumulation. Fluorescence and phase contrast images of the whole well (nine sites) were acquired at CENABIO (National Center of Structural Biology and Bioimage) with an environmentally controlled ImageXpress Micro system using a 10x objective and were analyzed by MetaXpress software (Molecular Devices, Sunnyvale, CA, USA).

\section{Cell viability and cell proliferation}

Cell viability was evaluated using MTT (3-(4,5-dimethylthiazol-2-yl)-2,5-diphenyltetrazolium bromide) tetrazolium-Sigma-Aldrich $®)$ assay according with manufacturer recommendation. Absorbance was immediately measured at $570 \mathrm{~nm}$ in microplate reader (Bio-Rad 2550). Results were expressed as percentage of undifferentiated group. Cell proliferation was monitored using bromo-2'-deoxy-uridine (BrdU) labeling and detection kit I (Roche Diagnostics) after 3, 21 and 27 days, according to manufacturer recommendation. DAPI staining was performed for cell counting at a 1:2000 dilution, for $15 \mathrm{~min}$ at room temperature. Positive cells were quantified using the immunofluorescence microscopy (ImageXpress) with an excitation wavelength from 450 to $500 \mathrm{~nm}$. Results were expressed as percentage of BrdU-positive cells related to total number of cells.

\section{Cell gene expression}

Total RNA from perigonadal adipose tissue (WT and NBR-KO) and 3T3-L1 cells was extracted using RNeasy lipid tissue micro kit (Qiagen) and cDNA obtained from $1 \mu \mathrm{g}$ of RNA or $2 \mu \mathrm{g}$ for NB, NB-R, GRP and GRP-R mRNA analysis, using the High-Capacity cDNA Reverse kit (Applied Biosystems). Products were amplified with specific primers (Table 1) on Mastercycler ${ }^{\circledR}$ Realplex 2 (Eppendorf) using EvaGreen qPCR Supermix (Solis Biodyne $^{\circledR}$, Elva, TA, Estonia), expect for NB, NB-R, GRP and GRP-R when the it was used the Maxima SYBR Green qPCR Master Mix (Thermo Scientific). Cycle parameters for all genes were $95^{\circ} \mathrm{C}$ for $15 \mathrm{~min}$, followed by 40 cycles at $95^{\circ} \mathrm{C}$ for $15 \mathrm{~s}, 60^{\circ} \mathrm{C}$ for $30 \mathrm{~s}$ and $72^{\circ} \mathrm{C}$ for $30 \mathrm{~s}$. Standard curve was used to calculate relative mRNA and all samples were corrected by 36B4 and HPRT, used as reference genes.

For perigonadal adipose tissue mRNA, the qPCR fragments were resolved in $2 \%$ agarose gel and visualized with a fluorescent nucleic acid gel stains Gel RedTM
(Biotium) under UV light exposition (ImageQuant LAS 4000 equipment - GE Healthcare Life Sciences).

\section{Statistical analysis}

Data were expressed as mean (standard error, s.e.) and GraphPad Prism 7 (GraphPad Prism Software, Inc.) was used. For adipogenic induction in ASC from mice adipose tissue, two-way ANOVA followed by Bonferroni post test was conducted. To all other experiments, one-way ANOVA followed by Tukey post test was performed. Statistically significant difference was considered as $P<0.05$.

\section{Results}

\section{Evaluation of in vitro differentiation of ASC from perigonadal adipose tissue of female NBR-KO mice}

In undifferentiated state, NBR-KO and WT cells accumulated lipids similarly (oil red staining - Fig. 1A and $\mathrm{B}$ ). In the presence of the adipogenic cocktail, lipid accumulation in WT cells was 1.84 times higher than in undifferentiated state and NBR-KO differentiated cells accumulated $44.9 \%$ less lipids than WT differentiated cells (Fig. $1 \mathrm{~A}$ and B, $P<0.05$ ).

$\mathrm{Nmb}$ mRNA is expressed in the perigonadal adipose tissue of WT and NBR-KO similarly and, as expected, $\mathrm{Nmbr}$ mRNA is only expressed in WT (Fig. 1C).

\section{Effect of neuromedin B receptor antagonist PD168368 on adipocyte differentiation of 3T3-L1 lineage cells}

3T3-L1 cells express the mRNA encoding for NB, NB-R and GRP-R (Fig. 2), but the Grp mRNA expression was not detectable. Nmb mRNA expression of differentiated cells at D3 showed a trend to be lower than that in undifferentiated condition $(P=0.06)$, but it was 1.6 -fold higher at D21 compared to D3 (Fig. 2B). There were no statistically significant differences on $\mathrm{Nmbr}$ and $\mathrm{Grpr}$ expression among D3 and D21, even though there is a trend to lower expression of Grpr mRNA at D21 compared to D3 in differentiated state $(P=0.08)$ (Fig. 2A and C).

At D3, differentiated CTR and DMSO (vehicle) groups presented higher number of cells (DAPI staining - Fig. 3B) and higher BrdU+ incorporation (Fig. 3C, 6x, $P<0.05)$ than undifferentiated group, corresponding to the expected high rate of cell proliferation. However, the differentiated antagonist group exhibited lower number of cells than controls $(-32 \%, P<0.05)$, and similar amount 
A
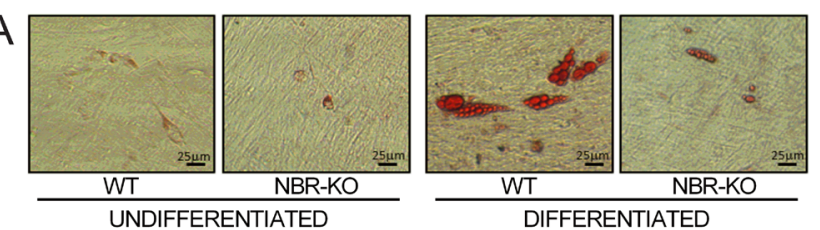

B

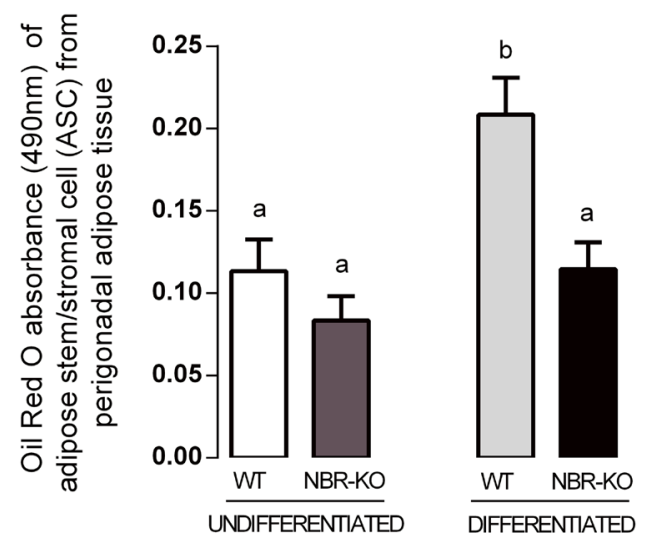

C Perigonadal adipose tissue Nmbr mRNA expression (224bp)

MW WT NBRKO RT- C-

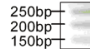
$250 \mathrm{bp}-$
$200 \mathrm{bp}-$
$150 \mathrm{bp}-$
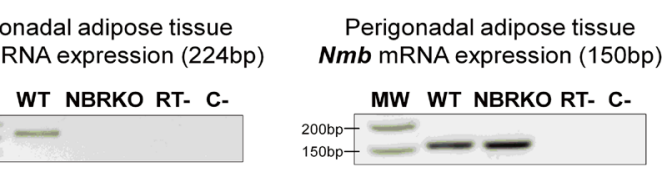

\section{Figure 1}

Lipid accumulation (Oil Red O staining) in adipose stem/stromal cells from the stromal vascular fraction of perigonadal white adipose tissue from female WT (wild type) and NBR-KO (neuromedin B receptor knockout) mice cultured without (undifferentiated) or under a differentiation protocol (differentiated). (A) Representative images. (B) Oil Red O absorbance. (C) Nmbr (neuromedin B receptor, 224 bp) and Nmb (neuromedin B, $149 \mathrm{bp}$ ) mRNA expression of perigonadal adipose tissue from WT and NBR-KO mice. C-, internal negative control; MW, molecular weight; RT, reverse transcriptase negative control. Data are expressed as mean and standard error. Two-way ANOVA followed by Bonferronni post test was conducted. Different letters mean statistically different groups $(P<0.05)$. A full colour version of this figure is available at https://doi. org/10.1530/JME-19-0032.

as undifferentiated (Fig. 3B), as well as significantly less proliferation than differentiated controls $(-53 \%, P<0.05)$, although higher than undifferentiated group (Fig. 3C, $P<0.05)$. Concordant with the initial stage of induced in vitro differentiation, lipid accumulation (BODIPY staining) was not statistically significant different among groups at D3 (Fig. 3D).

At D21, differentiated CTR and DMSO groups exhibited higher lipid area than undifferentiated group $(74 \times, P<0.05$, Fig. $3 \mathrm{H})$, while the antagonist group accumulated much less lipids than differentiated controls, comparing with the same area occupied by undifferentiated cells $(-86 \%, P<0.05$, Fig. $3 \mathrm{H})$. At D21, all the differentiated groups showed low rate of proliferation, with no differences among them (Fig. 3I), and the antagonist group continued to have lower number of cells than the differentiated control groups (Fig. 3G). As evaluated by MTT assay, at D3, the differentiated antagonist group exhibited less viable cells than the other differentiated groups $(-28 \%, P<0.05$, Fig. 3E), but this difference was not maintained at day 21 (Fig. 3J). Representative images are shown as transmitted light (TL), DAPI, BODIPY staining and BrdU staining at D3 (Fig. 3F) and D21 (Fig. 3K).

\section{Adipogenesis and lipogenesis genes expression in 3T3-L1 cells at day 3 and 21 of adipocyte differentiation}

Figure 4 depicts data from genes mRNA expressions of differentiated antagonist and DMSO (vehicle) groups. At D3 (Fig. 4A), the mRNA expression of Cebpb was lower in differentiated antagonist group (-39\%) and that of Cebpd mRNA was unaltered. Cebpa mRNA expression had no statistically significant differences among groups, while those of Pparg (-57\%), Fabp4 (-56\%), Plin1 (-50\%) and Adipoq (-59\%) were decreased. Srebf1 mRNA expression was similar between differentiated DMSO and antagonist groups, although it was higher than undifferentiated group. Acaca mRNA expression was not different among all groups, since it is not fully expressed at this period of in vitro differentiation (data not shown).

At D21 (Fig. 4B), adipocytes were fully matured and the mRNA expression of the Cebpb was similar between
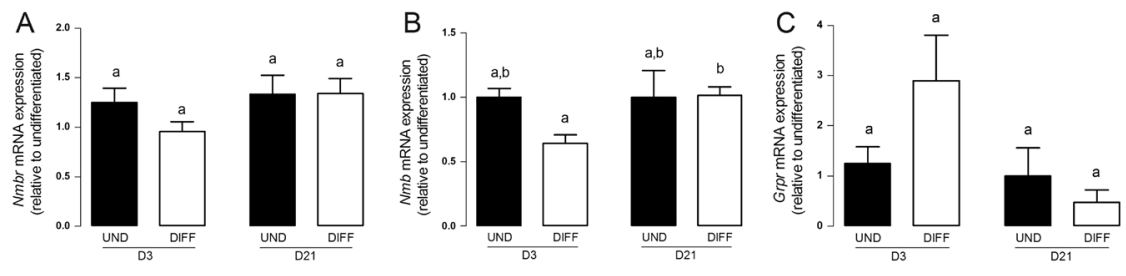

Figure 2

Expression of neuromedin B receptor, neuromedin B and GRP receptor mRNAs in 3T3-L1 cells at day 3 and 21 in culture under a differentiation protocol. mRNA expression of: (A) Nmbr, (B) Nmb and (C) Grpr. Values are relative to respective undifferentiated group. UND (undifferentiated) and DIFF (Differentiated) groups after 3 (D3) or 21 days (D21) of incubation. Data are expressed as mean and standard error. One-way ANOVA followed by Bonferronni post test was conducted. Different letters mean statistically different groups $(P<0.05)$. 

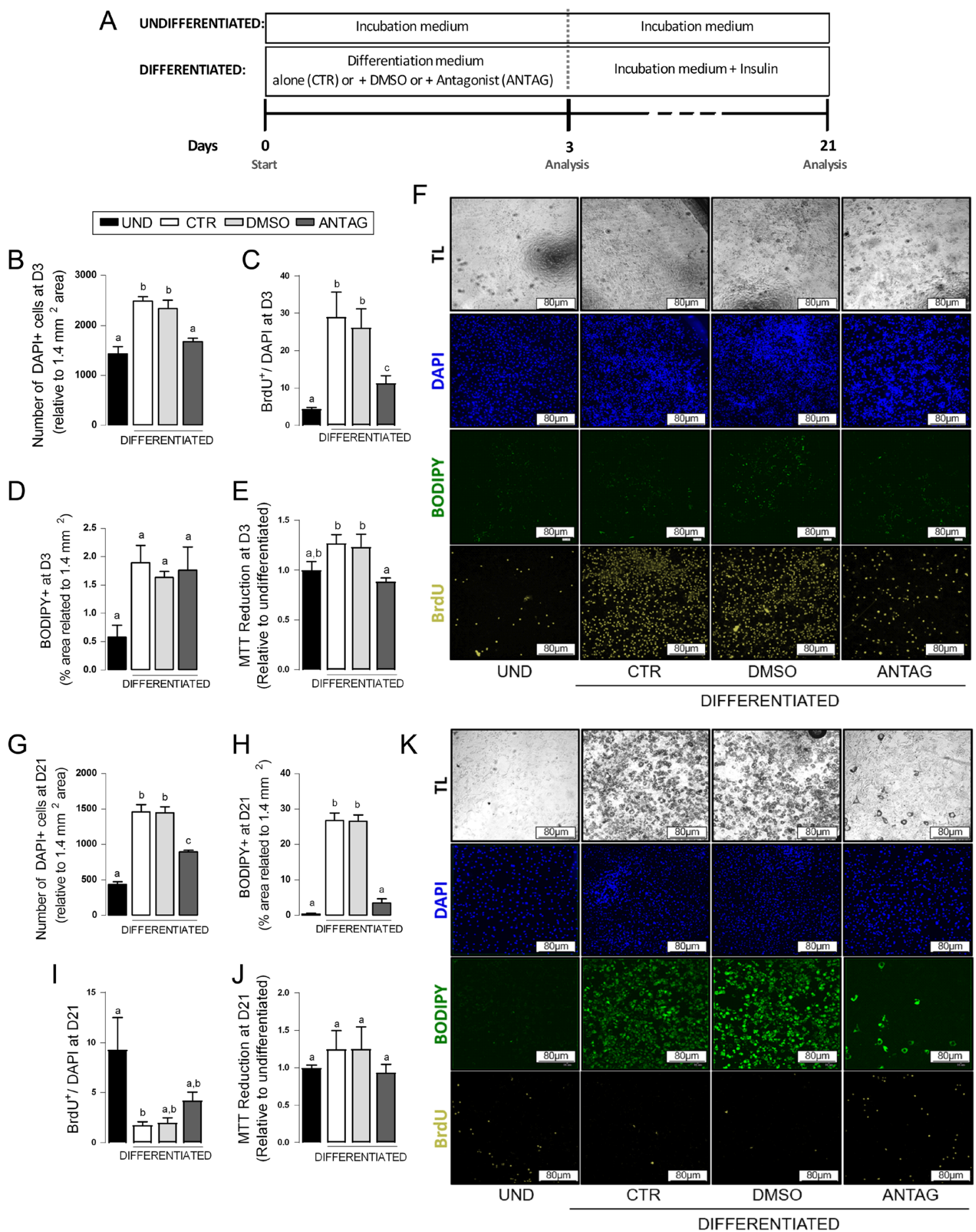

\section{Figure 3}

Effect of neuromedin B receptor antagonist PD168368 on adipogenic differentiation of 3T3-L1 lineage cells cultured under a differentiation protocol. (A) Experimental design. 3T3-L1 preadipocytes were cultured in incubation medium (UND) or differentiation medium containing incubation medium plus adipogenic cocktail, in the absence (CTR or DMSO, vehicle) or presence of NB-R antagonist PD168368 (ANTAG) until day 3 (D3) and, thereafter, cells were maintained in incubation medium in the absence (UND) or presence of insulin until day 21 (D21). Analyses were performed at D3 (B, C, D, E and F) and D21 (G, H, I, J and K). Number of cells (DAPI) at D3 (B) and at D21 (G); percentage of cell proliferation (BrdU+ incorporation/number of cells) at D3 (C) and D21 (I); lipid accumulation at D3 (D) and D21 (H); cell viability at D3 (E) and D21 (J). Graphs represent nine sites per well corresponding to 1.4 mm². Data are expressed as mean and standard error. One-way ANOVA, followed by Tukey post test was conducted. Different letters mean statistically different groups $(P<0.05)$. ( $F$ and $K)$ Representative images of transmitted light $(T L)$, number of cells (DAPI), lipid accumulation (BODIPY) and cell proliferation $\left(\mathrm{BrdU}^{+}\right)$at D3 (F) and D21 (K). UND (undifferentiated), CTR (control), DMSO (dimethylsufoxide), ANTAG (NB-R antagonist PD168368). 

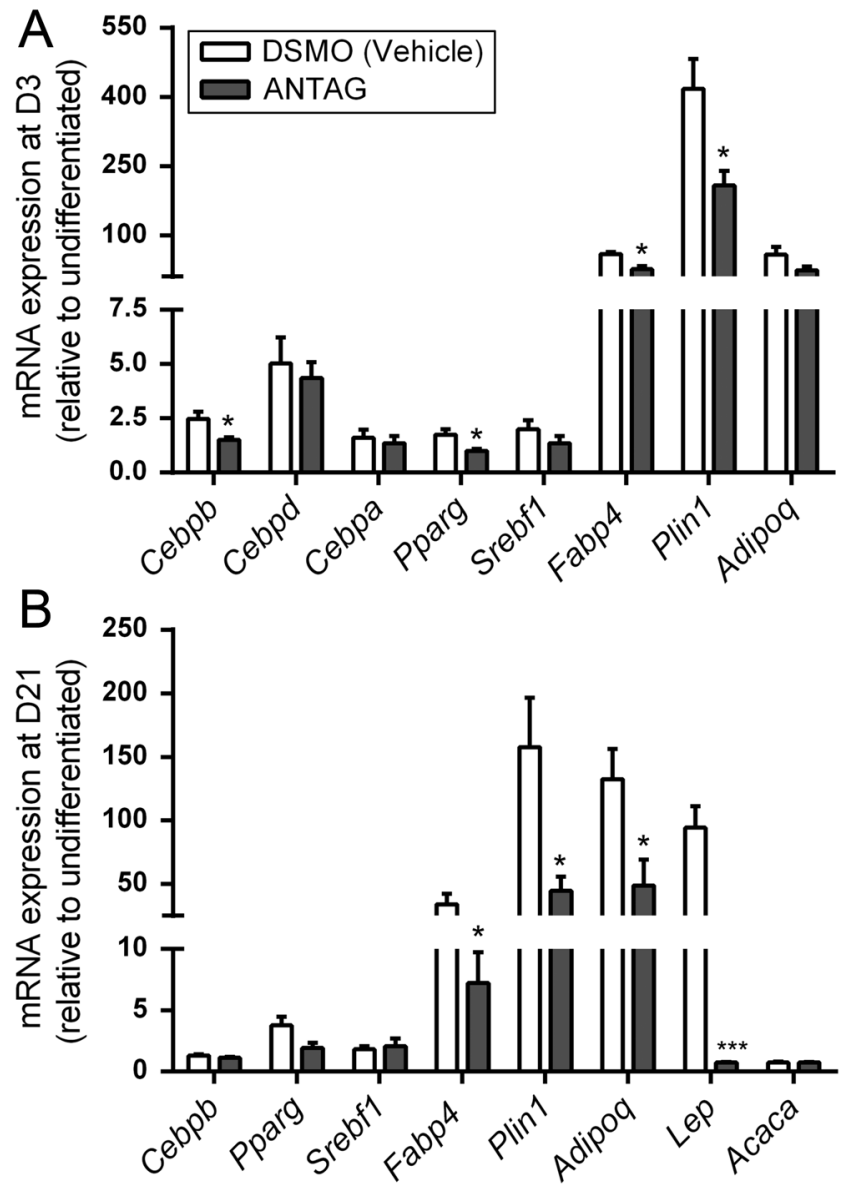

\section{Figure 4}

Effect of neuromedin B receptor antagonist PD168368 on adipogenesis and lipogenesis-related genes expression in 3T3-L1 cells at day 3 (A) and day 21 (B) in culture under a differentiation protocol. mRNA expression of: Cebpb, Cebpd, Cebpa, Pparg, Srebp1, Fabp4, Plin1, Adipoq, Lep, Acaca. Values are relative to undifferentiated group. DMSO (dimethylsufoxide) and ANTAG (NB-R antagonist PD168368). Data are expressed as mean and standard error. One-way ANOVA followed by Tukey post test was conducted $\left({ }^{*} P<0.05\right)$.

differentiated groups, as well as the mRNA of Cebpd and Cebpa (data not shown). Pparg mRNA showed a trend for lower expression $(-49 \%, P=0.1)$ in the differentiated antagonist group, and Srebf1 mRNA was not different between groups. Differentiated antagonist group exhibited lower mRNA expression of Fabp4 (-79\%), Plin1 (-72\%), Adipoq (-63\%) and Lep (-89\%). Acaca mRNA did not differ significantly between the DMSO group and antagonist group. The differentiated DMSO and CTR group showed similar responses regarding all gene expressions (data not shown), except for Acaca mRNA expression which was significantly reduced compared to differentiated control group, but not to DMSO group.

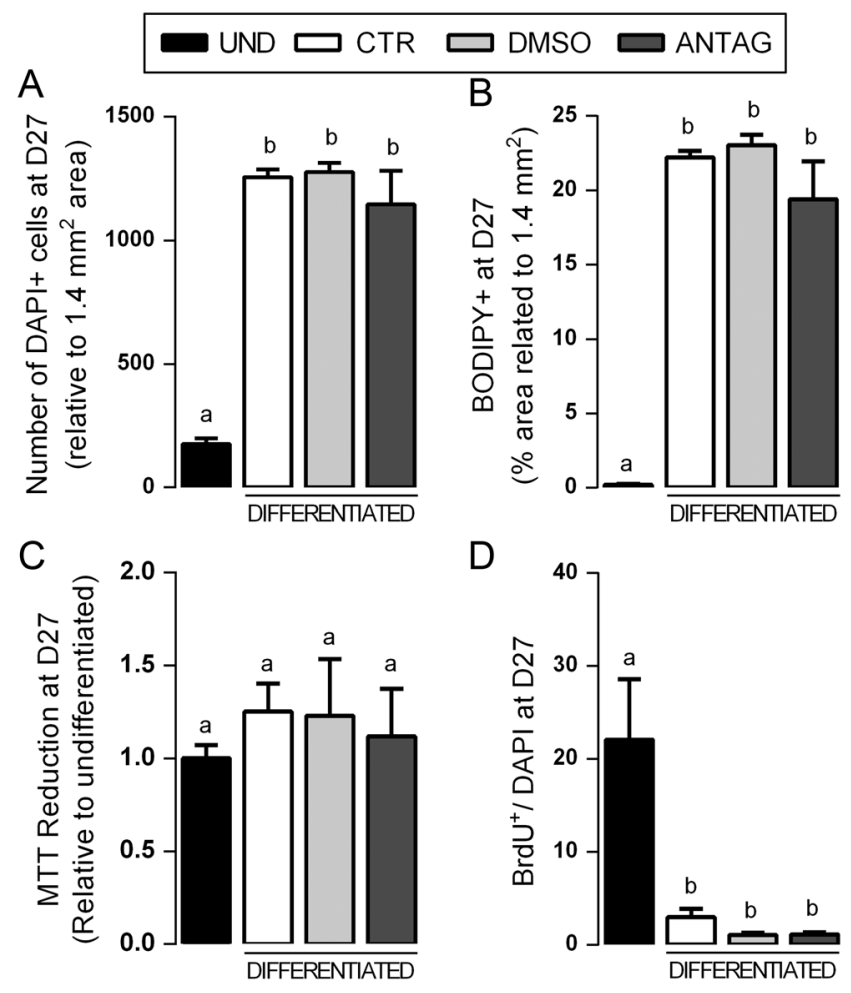

Figure 5

Effect of neuromedin B receptor antagonist PD168368 on mature 3T3-L1 cells. Cells were cultured until full adipocyte differentiation and at day 21 the antagonist was added to the medium and cells were harvested to analysis at the day 27 (D27). (A) Number of cells (DAPI), (B) lipid accumulation (BODIPY), (C) cell viability (MTT reduction) and (D) cell proliferation (BrdU+) at D27. UND (undifferentiated), CTR (control), DMSO (dimethylsufoxide), ANTAG (NB-R antagonist PD168368). Data are expressed as mean and standard error. One-way ANOVA followed by Tukey post test was conducted. Different letters mean statistically different groups $(P<0.05)$.

\section{Effect of neuromedin B receptor antagonist PD168368 on mature 3T3-L1 cells}

Fully differentiated adipocytes at day 27 , which were incubated or not with the antagonist of NB-R added at day 21, showed similar responses, regarding number of cells, lipid area, cell viability and cell proliferation (Fig. 5), as well as in mRNA expression of adipocyte genes studied (data not shown). Therefore, the antagonist of NB-R PD168368 had no effect on lipid accumulation or cell viability in mature adipocytes.

\section{Discussion}

The present study showed that disruption of neuromedin $\mathrm{B}$ receptor impairs adipogenesis in vitro in response to 
adipogenic cocktail, both in ASC from perigonadal white adipose tissue of female mice lacking the neuromedin B receptor and in preadipocytes 3T3-L1 cells.

ASC from stromal vascular fraction of adipose tissue extracted from perigonadal white adipose tissue of NBR-KO mice exhibited an important decrease in adipogenic differentiation, as demonstrated by the marked lower lipid accumulation, revealing impaired ability to fully mature. Other possibility that we cannot exclude is that the ASC of NBR-KO mice contained a reduced number of cells committed to the adipogenic lineage (preadipocytes).

Additionally, 3T3-L1 cells incubated with the pharmacological antagonist of the neuromedin $\mathrm{B}$ receptor, PD168368, during the first 3 days in culture, exhibited reduced markers of adipocyte differentiation and maturation.

The antagonist of NB-R reduced the rate of proliferation, which probably accounts for the reduced number of cells and the lower number of viable cells. Even though we cannot exclude the occurrence of apoptosis, the data suggest that the antagonist interfered with cell proliferation at this first step of differentiation, the clonal expansion. Indeed, an anti-proliferative effect of antagonist PD168368 had been reported in mammary cancer cell line MDA-MB-23 by mechanisms involving cell cycle arrest (Park et al. 2011). In addition, neuromedin $\mathrm{B}$ induced mitogenesis in quiescent 3T3 fibroblasts acting via its preferential receptor (Zachary \& Rozengurt 1985, Feldman et al. 1996). Our study, and a previous one (Hoggard et al. 2007) showed that Nmb mRNA expression in $3 \mathrm{~T} 3$ cells is higher at undifferentiated stage followed by a decrease, observed few days after initial differentiation, which may indicate a role for NB activating the receptor in the initial stage of adipogenic differentiation, still to be further explored.

The neuromedin B receptor antagonist attenuated the induction of the mRNA expression encoding CBEP $\beta$ and PPAR $\gamma$, early expressed differentiating transcription factors (Farmer 2006). Besides inducing PPAR $\gamma$ expression, СЕВP $\beta$ has a role in inducing clonal expansion (Zhang et al. 2011, Guo et al. 2015), and it is possible that the antiproliferative effect of the NB-R antagonist is related, at least, in part, to the lower expression of СЕВР $\beta$. The reduced induction of PPAR $\gamma$ is likely pivotal for the effect of the NB-R antagonist resulting in reduced expression of its target genes early expressed, such as those encoding perilipin, FABP4 and adiponectin (Ruiz-Ojeda et al. 2016). The lower lipid content per area occupied observed at late stages in culture suggests reduced ability to accumulate lipids in the cells exposed to the antagonist. In agreement, the expressions of genes essential to lipogenesis were greatly reduced also at D21, such as perilipin 1 and FAPBP4. However, there is no alteration in the expression of the gene encoding acetyl-CoA carboxylase, key enzyme in the fatty acid synthesis (Itabe et al. 2017), maybe, because the induction of the enzyme occurs at advanced stages in 3T3-L1 differentiation, when the incubation medium had no antagonist. Another possibility is related to unaltered expression of the gene encoding SREPB1, that importantly induce the lipogenic proteins (Kim \& Spiegelman 1996, Rosen et al. 2000).

The PD168368 compound is a nonpeptide ligand characterized as a high-affinity NB-R competitive antagonist. For instance in Balb-c transfected cells with rodent GRP-R or NB-R, the Ki was $2151 \mathrm{nM}$ and $45 \mathrm{nM}$, respectively, and higher than 10,000 in cells transfected with human BRS3 (Ryan et al. 1999). The antagonist has no intrinsic activity and has been shown to block NB effects through NB-R (Ryan et al. 1999, Park et al. 2011). Although both NB-R and GRP-R are present in 3T3-L1 cells, since the affinity of the GRP receptor is reported to be 30- to 60-fold lower than that of NB-R for PD168368 (Ryan et al. 1998), and Grp mRNA was not detected, we interpreted the anti-adipogenic effects of PD168368 as a consequence of blocking the autocrine effect of neuromedin B, acting through NB-R. However, it cannot be discarded that PD16368 also antagonizes GRP receptor. Future studies addressing curve dose responses of NB and GRP incubation with PD16368 will be necessary to clarify these questions.

From our results, we presume that the blockage of NB-R, in primary cells (ASC), and in the lineage cells (3T3L1) interferes with the action of adipogenic agents added to the medium, which include, isobutylmethylxanthine (to increase intracellular cAMP), dexamethasone and insulin. However, the precise mechanisms require further studies. NB receptor is a $G$ protein-coupled receptor, which signals primarily through phospholipase C-mediated cascades, modifying the levels of cytosolic calcium and activation of PKC (Ryan et al. 1998). No signaling through cAMP has been demonstrated. In addition, NB-R activates the PI3K pathway resulting in ERK1 and ERK2 and AKT phosphorylation - pathway directly involved in cellular proliferation and survival in tumors (Park et al. 2009, 2011). Interestingly, some $\mathrm{G}$ protein-coupled receptors agonists, among them neuromedin B, are able to induce insulin receptor signaling in the complete absence of insulin in rat hepatoma cell lines (Alghamdi et al. 2014, Haxho et al. 2018). Therefore, the blockage of the neuromedin $B$ receptor may potentially result in disruption of a variety 
of cellular signaling pathways important to adipogenesis. The fact that neuromedin B receptor antagonist attenuated the induction of CBEP $\beta$ and PPAR $\gamma$ mRNA expression, but not that of C/EBP $\alpha$ or SREBP 1 suggest some specificity in its mechanism of action that will be important to be established in future studies.

Regardless of the mechanism, the modulation of NB receptor activity may represent a promising target for limiting the gain weight associated with cell hyperplasia that occurs in the genesis of obesity, but not to induce loss of adiposity through lipolysis, since mature cells were not affected by the antagonist. The fact that neuromedin B receptor-knockout ASC from perigonadal adipose tissue also did not respond properly to the adipogenic agents in culture indicates that it is not a phenomenon restricted to a particular cell line used here, 3T3-L1, but also exist in vivo. As we have shown before, female NB-R knockout mice maintained in normolipidic diet have no alteration in white adipose mass or body weight, but in response to a high-fat diet they exhibited less adiposity and lower body weight than WT fed the same high-fat diet (Paula et al. 2010). In vivo, ASC and preadipocytes retain the capacity to differentiate to form mature adipocytes throughout life, and we propose that NB and NB-R are involved in modulating effects of nutritional and hormonal factors that induce adipogenesis in response to stimuli in vivo, such as hypercaloric diets. Altogether the data point to a role of neuromedin B receptor in adipogenesis of perigonadal female mice, an effect that needs to be confirmed to other depots and, also in white adipose tissue of male mice. Our unpublished data suggest that the phenotype of high-fat diet-treated NBR-KO in male mice is not as evident as in females, and also that estrogen stimulates NB expression in perigonadal white adipose tissue in ovariectomized rats. However, sex differences will have to be addressed in future studies.

In conclusion, genetic disruption of NB-R in female mice ASC or pharmacological antagonism of NB-R in 3T3-L1 cells impairs induced adipogenesis in vitro. The mechanisms suggested by results in 3T3-L1 cells involve reduction of cell proliferation and of early gene expressions, leading to decreased number of mature adipocytes. Even though precise mechanisms are still undefined, this study highlights a new player in adipogenesis and, together with our previous observation of partial resistance to develop diet-induced obesity in female NBR-knockout mice, lead us to suggest that potentially the modulation of $\mathrm{NB}$ receptor activity represents a promising target for limiting the increase in adiposity.

\section{Declaration of interest}

The authors declare that there is no conflict of interest that could be perceived as prejudicing the impartiality of the research reported.

\section{Funding}

Research supported by Conselho Nacional de Desenvolvimento Científico e Tecnológico (CNPq), grant 401194/2014-0, and Fundação Carlos Chagas Filho de Amparo a Pesquisa do Estado do Rio de Janeiro (FAPERJ), grants $110.108 / 2013$ and 202.924/2015.

\section{Acknowledgements}

The authors thank Dr Viviane G Gomes (National Center of Structural Biology and Bioimage - CENABIO, Federal University of Rio de Janeiro) for assistance with the high-content cell imaging assay.

\section{References}

Alghamdi F, Guo M, Abdulkhalek S, Crawford N, Amith SR \& Szewczuk MR 2014 A novel insulin receptor-signaling platform and its link to insulin resistance and type 2 diabetes. Cellular Signalling 26 1355-1368. (https://doi.org/10.1016/j.cellsig.2014.02.015)

Farmer SR 2006 Transcriptional control of adipocyte formation. Cell Metabolism 4 263-273. (https://doi.org/10.1016/j.cmet.2006.07.001)

Feldman RI, Bartholdi MF \& Wu JM 1996 Bombesin-like peptide receptor subtypes promote mitogenesis, which requires persistent receptor signaling. Molecular Pharmacology 50 1346-1354.

Gorbulev V, Akhundova A, Büchner H \& Fahrenholz F 1992 Molecular cloning of a new bombesin receptor subtype expressed in uterus during pregnancy. European Journal of Biochemistry 208 405-410. (https://doi.org/10.1111/j.1432-1033.1992.tb17201.x)

Guo L, Li X \& Tang QQ 2015 Transcriptional regulation of adipocyte differentiation: a central role for CCAAT/enhancer-binding protein (C/EBP) $\beta$. Journal of Biological Chemistry 290 755-761. (https://doi. org/10.1074/jbc.R114.619957)

Haxho F, Haq S \& Szewczuk MR 2018 Biased G protein-coupled receptor agonism mediates Neu1 sialidase and matrix metalloproteinase- 9 crosstalk to induce transactivation of insulin receptor signaling. Cellular Signalling 43 71-84. (https://doi.org/10.1016/j. cellsig.2017.12.006)

Hoggard N, Bashir S, Cruickshank M, Miller JD \& Speakman JR 2007 Expression of neuromedin B in adipose tissue and its regulation by changes in energy balance. Journal of Molecular Endocrinology 39 199-210. (https://doi.org/10.1677/JME-07-0071)

Itabe H, Yamaguchi T, Nimura S \& Sasabe N 2017 Perilipins: a diversity of intracellular lipid droplet proteins. Lipids in Health and Disease 16 83. (https://doi.org/10.1186/s12944-017-0473-y)

Kameda H, Miyoshi H, Shimizu C, Nagai S, Nakamura A, Kondo T, Chida D \& Atsumi T 2014 Expression and regulation of neuromedin B in pituitary corticotrophs of male melanocortin 2 receptordeficient mice. Endocrinology 155 2492-2499. (https://doi. org/10.1210/en.2013-2077)

Kim JB \& Spiegelman BM 1996 ADD1/SREBP1 promotes adipocyte differentiation and gene expression linked to fatty acid metabolism. Genes and Development 10 1096-1107. (https://doi.org/10.1101/ gad.10.9.1096)

Ladenheim EE, Hampton LL, Whitney AC, White WO, Battey JF \& Moran TH 2002 Disruptions in feeding and body weight control in gastrin-releasing peptide receptor deficient mice. Journal of Endocrinology 174 273-281. (https://doi.org/10.1677/joe.0.1740273) 
Ma Z, Zhang Y, Su J, Yang S, Qiao W, Li X, Lei Z, Cheng L, An N, Wang W, et al. 2018 Effects of neuromedin B on steroidogenesis, cell proliferation and apoptosis in porcine Leydig cells. Journal of Molecular Endocrinology 61 13-23. (https://doi.org/10.1530/JME-170242)

McDonald TJ, Jörnvall H, Nilsson G, Vagne M, Ghatei M, Bloom SR \& Mutt V 1979 Characterization of a gastrin releasing peptide from porcine non-antral gastric tissue. Biochemical and Biophysical Research Communications 90 227-233. (https://doi.org/10.1016/0006291X(79)91614-0)

Minamino N, Kangawa K \& Matsuo H 1983 Neuromedin B: a novel bombesin-like peptide identified in porcine spinal cord. Biochemical and Biophysical Research Communications 114 541-548. (https://doi. org/10.1016/0006-291X(83)90814-8)

Ohki-Hamazaki H, Watase K, Yamamoto K, Ogura H, Yamano M, Yamada K, Maeno H, Imaki J, Kikuyama S, Wada E, et al. 1997 Mice lacking bombesin receptor subtype-3 develop metabolic defects and obesity. Nature 390 165-169. (https://doi. org/10.1038/36568)

Ohki-Hamazaki H, Sakai Y, Kamata K, Ogura H, Okuyama S, Watase K, Yamada K \& Wada K 1999 Functional properties of two bombesinlike peptide receptors revealed by the analysis of mice lacking neuromedin B receptor. Journal of Neuroscience 19 948-954. (https:// doi.org/10.1523/JNEUROSCI.19-03-00948.1999)

Oliveira KJ, Ortiga-Carvalho TM, Cabanelas A, Veiga MA, Aoki K, OhkiHamazaki H, Wada K, Wada E \& Pazos-Moura CC 2006 Disruption of neuromedin $\mathrm{B}$ receptor gene results in dysregulation of the pituitary-thyroid axis. Journal of Molecular Endocrinology 36 73-80. (https://doi.org/10.1677/jme.1.01892)

Park HJ, Kim SR, Bae SK, Choic YK, Bae YH, Kim EC, Kim WJ, Jang HO, Yun I, Kim YM, et al. 2009 Neuromedin B induces angiogenesis via activation of ERK and Akt in endothelial cells. Experimental Cell Research 315 3359-3369. (https://doi.org/10.1016/j. yexcr.2009.08.009)

Park HJ, Kim SR, Kim MK, Choi KS, Jang HO, Yun I, Bae SK \& Bae MK 2011 Neuromedin B receptor antagonist suppresses tumor angiogenesis and tumor growth in vitro and in vivo. Cancer Letters 312 117-127. (https://doi.org/10.1016/j.canlet.2011.08.014)

Paula GSM, Souza LL, Cabanelas A, Bloise FF, Mello-Coelho V, Wada E, Ortiga-Carvalho TM, Oliveira KJ \& Pazos-Moura CC 2010 Female mice target deleted for the neuromedin B receptor have partial resistance to diet-induced obesity. Journal of Physiology $\mathbf{5 8 8}$ 1635-1645. (https://doi.org/10.1113/jphysiol.2009.185322)
Paula GSM, Souza LL, Bressane NOS, Maravalhas R, Wilieman M, BentoBernardes T, Silva KR, Mendonça LS, Oliveira KJ \& Pazos-Moura CC 2016 Mice with deletion of neuromedin B receptor exhibit decreased oral glucose-stimulated insulin release. Hormone and Metabolic Research 48 854-861. (https://doi.org/10.1055/s-0042-115643)

Rosen ED, Walkey CJ, Puigserver P \& Spiegelman BM 2000 Transcriptional regulation of adipogenesis. Genes and Development $\mathbf{1 4}$ 1293-1307. (https://doi.org/10.1101/gad.14.11.1293)

Ruiz-Ojeda FJ, Rupérez AI, Gomez-Llorrente C, Gil A \& Aguilera CM 2016 Cell models and their application for studying. Adipogenic differentiation in relation to obesity: a review. International Journal of Molecular Sciences 17 E1040. (https://doi.org/10.3390/ijms17071040)

Ryan RR, Weber HC, Hou W, Sainz E, Mantey SA, Battey JF, Coy DH \& Jensen RT 1998 Ability of various bombesin receptor agonists and antagonists to alter intracellular signaling of the human orphan receptor BRS-3. Journal of Biological Chemistry 273 13613-13624. (https://doi.org/10.1074/jbc.273.22.13613)

Ryan RR, Katsuno T, Mantey SA, Pradhan TK, Weber HC, Coy DH, Battey JF \& Jensen RT 1999 Comparative pharmacology of the nonpeptide neuromedin B receptor antagonist PD 168368. Journal of Pharmacology and Experimental Therapeutics 290 1202-1211.

Spindel ER, Giladi E, Brehm P, Goodman RH \& Segerson TP 1990 Cloning and functional characterization of a complementary DNA encoding the murine fibroblast bombesin/gastrin-releasing peptide receptor. Molecular Endocrinology 4 1956-1963. (https://doi. org/10.1210/mend-4-12-1956)

von Schrenck T, Heinz-Erian P, Moran T, Mantey SA, Gardner JD \& Jensen RT 1989 Neuromedin B receptor in esophagus: evidence for subtypes of bombesin receptors. American Journal of Physiology 256 G747-G758. (https://doi.org/10.1152/ajpgi.1989.256.4.G747)

Yang YS, Song HD, Li RY, Zhou LB, Zhu ZD, Hu RM, Han ZG \& Chen JL 2003 The gene expression profiling of human visceral adipose tissue and its secretory functions. Biochemical and Biophysical Research Communications 300 839-846. (https://doi.org/10.1016/S0006291X(02)02843-7)

Zachary I \& Rozengurt E 1985 High-affinity receptors for peptides of the bombesin family in Swiss 3T3 cells. PNAS 82 7616-7620. (https:// doi.org/10.1073/pnas.82.22.7616)

Zhang YY, Li X, Qian SW, Guo L, Huang HY, He Q, Liu Y, Ma CG \& Tang QQ 2011 Transcriptional activation of histone H4 by C/EBP during the mitotic clonal expansion of 3T3-L1 adipocyte differentiation. Molecular Biology of the Cell 22 2165-2174. (https:// doi.org/10.1091/mbc.E10-11-0912)

Received in final form 17 April 2019

Accepted 8 May 2019

Accepted Preprint published online 8 May 2019 (c) 2019 Society for Endocrinology Published by Bioscientifica Ltd. Printed in Great Britain 